\title{
Homebound patients' perspectives on technology and telemedicine: A qualitative analysis
}

\section{Citation}

Huang, Kristin T. L., Tracy J. Lu, Forootan Alizadeh, and Arash Mostaghimi. 2016. “Homebound Patients' Perspectives on Technology and Telemedicine: A Qualitative Analysis." Home Health Care Services Quarterly 35 (3-4) (October): 172-181. doi:10.1080/01621424.2016.1264341.

\section{Published Version}

doi:10.1080/01621424.2016.1264341

\section{Permanent link}

http://nrs.harvard.edu/urn-3:HUL.InstRepos:37058131

\section{Terms of Use}

This article was downloaded from Harvard University's DASH repository, and is made available under the terms and conditions applicable to Open Access Policy Articles, as set forth at http:// nrs.harvard.edu/urn-3:HUL.InstRepos:dash.current.terms-of-use\#OAP

\section{Share Your Story}

The Harvard community has made this article openly available.

Please share how this access benefits you. Submit a story.

Accessibility 
LRH K. T. L. HUANG ET AL.

RRH HOME HEALTH CARE SERVICES QUARTERLY

\section{Homebound Patients' Perspectives on Technology and Telemedicine: A Qualitative Analysis}

Kristin T. L. Huang, M.D., ${ }^{\text {a,b }}$ Tracy J. Lu, B.A., ${ }^{\mathrm{c}}$ Forootan Alizadeh, ${ }^{\mathrm{d}}$ and Arash Mostaghimi, MD, MPA, MPH ${ }^{\mathrm{c}, \mathrm{e}}$

${ }^{a}$ Division of Internal Medicine and Adult Primary Care, Tufts Medical Center, Boston, Masachusetts, USA

bepartment of Internal Medicine, Brigham and Women's Hospital, Boston, Masachusetts, USA;

${ }^{\mathrm{c}}$ Harvard Medical School, Boston, Masachusetts, USA

${ }^{\mathrm{d}}$ University of Massachusetts, Boston, Masachusetts, USA

eDepartment of Dermatology, Brigham and Women's Hospital, Boston, Masachusetts, USA

CONTACT Arash Mostaghimi, MD, MPA, MPH amostaghimi@bwh.harvard.edu,Brigham and Women's Hospital, 75 Francis Street, PBB-B 421, Boston, MA 02115, USA. 


\begin{abstract}
Telemedicine holds promise in bridging the gap between homebound patients and high quality health care, but uptake of such technology remains limited. Qualitative interviews conducted with 17 homebound patients found two major barriers to telemedicine. First, participants who lack familiarity with technology are hesitant about telemedicine, as baseline use of technology in the home is limited, participants did not feel capable of learning, and the advantages of telemedicine were unclear. Second, homebound patients place a high value on inoffice visits due to therapeutic benefit, face-to-face communication, and the social aspect of medical appointments.
\end{abstract}

KEYWORDS Community and home care; home health care; engaged technology; literacy technology; service delivery/utilization; technology

\title{
Introduction
}

\section{Homebound Patients}

In 2011, approximately 20 percent (over 7 million adults) of community-dwelling Medicare patients in the U.S. were considered semi- (15\%), mostly (4\%), or completely (1\%) homebound, as defined by frequency of leaving the home and whether leaving the home presents great difficulty or requires assistance (Ornstein et al., 2015). In the same year, three million people received Medicare home health care services (Centers for Medicare \& Medicaid Services, 2012). These patients are often isolated, medically frail, and incur high costs of care, while 
facing burdensome medical conditions, financial stressors, and difficulties in access to care (U.S. Department of Health and Human Services, 2012).

\section{Telemedicine in Homebound Patients}

Given homebound patients' challenges in accessing care and high burden of disease, telemedicine is well-positioned to address gaps in homebound health care by providing care without requiring transportation to a clinical setting. Recent randomized controlled trials of homebound patients have shown that telemedicine interventions can improve outcomes in depression as well as reduce emergency room visits in chronic obstructive pulmonary disease and heart failure (Choi et al., 2014b; Gellis et al., 2012; Gellis, Kenaley, \& Ten Have, 2014). Observational studies have found promising results in telemonitoring of chronic wounds in homebound patients, in providing dental consults and education to the homebound elderly over computers, and in depression management of both English- and Spanish-speaking homebound patients with therapy via videoconference (Rees \& Bashshur, 2007; Sheeran et al., 2011; Tomuro, 2004). Several of these studies have demonstrated that once homebound patients experience telemedicine, they have very high rates of acceptance and approval (Choi et al., 2014c; Finkelstein et al., 2014; Gellis et al., 2012).

While telemedicine interventions are well-accepted and efficacious in patients who are willing to use them, a substantial proportion of homebound patients - up to 80 to 90 percent remain resistant to even trying to use these types of technology (Choi, Wilson, Sirrianni, Marinucci, \& Hegel, 2014a; Finkelstein et al., 2014). Currently, only $21 \%$ of home health agencies offer telemedicine services (National Association for Home Care and Hospice, 2008). Without greater widespread willingness to participate in telemedicine interventions, the benefits of increased access, improved outcomes, and cost savings of telemedicine will remain limited. 
The goal of this study was to use qualitative interviews to investigate the attitudes of homebound patients towards technology and telemedicine in order to identify and characterize impediments to telemedicine acceptance.

\section{Methods}

\section{Participants}

Participants were recruited from patients receiving visiting nurse services from Upham's Home Care (a home care agency affiliated with a community health center) or from patients receiving services at Brigham and Women's Angiogenesis and Wound Healing Center. Inclusion criteria included patients who were 18 or older, met the Medicare definition of homebound, had received home care services for at least 1 month, and were English-speaking (Centers for Medicare \& Medicaid Services, 2013). Patients who were unable to participate in interviews due to cognitive impairment were excluded. Participants were recruited from a pool of homebound patients identified by partner organizations. Other than a consideration for gender balance patients were selected randomly from this pool. A total of 17 participants were recruited.

A quality improyement IRB exemption was granted from the Harvard Medical School and the Partners Healthcare IRBs. All participants gave verbal and written consent to be interviewed and to have their interviews recorded.

\section{Study Design}

An interview guide was constructed around major themes for exploration, including homebound patients' views on communication with their healthcare providers and technology. The guide served as a template for each participant interview, with flexibility to pursue relevant 
topics important to patients in more depth. We refined the questions and adjusted the guide iteratively as new themes of interest emerged. Two trained interviewers conducted the interviews jointly from May to July 2015. Each interview lasted approximately 45 to 90 minutes and was recorded. Interviews were mostly conducted in patients' homes, though some were conducted at the Brigham and Women's Angiogenesis and Wound Healing Center in tandem with an office visit per patient preference.

\section{Analysis}

After each interview, the two interviewers debriefed to identify key themes. Each interview was transcribed. Two of our researchers independently and inductively created coding categories to capture the major themes. Each transcript was coded using the immersion/crystallization technique to iteratively extract and describe the main points from each interview (Crabtree \& Miller, 1999; Criss et al., 2015; Crotty et al., 2015; Dallaghan, Hoffman, Lyden, \& Bevil, 2016; Matthias et al., 2016; Mohamed et al., 2014). We jointly reviewed the coded transcripts and reconciled the codes by consensus. During this process, we identified new codes as well as subthemes. We organized the transcript segments as well as the corresponding codes and subthemes in Microsoft Excel 2013. For the purpose of this analysis, one of us identified all the segments pertaining to technology or communication, and using the immersion/crystallization technique, analyzed the transcripts for the main learning points related to telemedicine (Crabtree \& Miller, 1999). These were then reviewed by our team until consensus was reached. 


\section{Results}

\section{Patient Characteristics}

Of the 17 participants, seven were male and ten were female, ranging in age from 25 to 86 years old. Thirteen were recruited from Upham's Home Care and four were recruited from Brigham and Women's Dermatology Chronic Wound Clinic. Of the participants, ten were African American, six were Caucasian, and one was Latino.

\section{General Attitudes}

Overall, nine participants had a largely negative view towards telemedicine, while five were open to trying it. Three had mixed opinions, with negative views towards videoconferencing and positive views towards telemonitoring devices.

\section{Barriers to Telemedicine in Homebound Patients}

Concerns about technology. One broad area of concern participants had regarding telemedicine were the challenges associated with using technology paired with uncertain advantages.

Lack of familiarity with technology. Only 6 of the 17 participants had a computer in the house and only 2 owned smartphones. Three patients with computers reported that they did not use them. For example, one participant who lived with her extended family mentioned her children and grandchildren used the computer, but she did not know how to use it, and she preferred a regular "flip" cell phone to the smartphone that her daughter had given her.

Participants voiced that one large concern with regards to communicating with clinicians using smart phones, videoconferencing, or computers was that they did not own the appropriate 
devices and were not familiar with how to use these types of technology. This baseline disconnect with technology seemed to perpetuate further disengagement: "I don't know how to use a computer; I'm not interested."

Perceived inability to learn. Even if the necessary telemedicine equipment were provided, several participants expressed doubts in their ability to learn how to use them: "I am totally idiotic with computers. I have a friend who used to work with me. He said, 'I'm going to teach you how to use that computer if I die.' I said okay. He spent days and days and I can't even open the stupid computer."

Many of the older participants mentioned their age as they accounted for their discomfort with technology. One participant protested, 'I'm an old man, not a young man; if I'm young, I'd need that" while another dismissed cell phones, computers, and other technology as belonging to "a different age.... a different generation." Functional accessibility of technological devices was also an issue given patients' physical constraints. Two participants mentioned their inability to use a cell phone or smartphone as the numbers were too small for them to see or feel, and another stated her disease-ridden hands prevented her from using a computer.

Unclear advantages of telemedicine. Many participants stated they had no interest in learning to use new technology. Several stated that they would not want telemedicine-enabled monitoring equipment because it would take too much effort to learn and to use regularly when their visiting nurse could measure the same parameters for them; some patients mentioned they'd rather just go to the doctor's office. Many patients voiced skepticism that telemedicine could bring benefits over conventional health care with comments such as "I'm not sure about that" and "I don't need that." 
Value of in-person clinical encounters. The second major reason that many participants were not keen on telemedicine was due to a strong preference to see their health care providers in person, despite the difficulties in getting to appointments.

\section{Benefits of in-person evaluation, diagnosis, and therapeutic interventions. Several}

participants stated that being seen in person would facilitate a more thorough evaluation,

including undergoing a physical examination "to make sure everything is working properly" and receiving appropriate diagnostic testing such as an electrocardiogram or laboratory tests.

Participants appreciated the therapeutic touch that an in-person visit to their clinician provides: “[With videoconferencing], they couldn't touch me - I think that's important. They can't treat me that well just from a TV." Participants also mentioned specific therapeutic procedures, such as wound debridement, that could only happen in person.

Preference for face-to-face communication. Participants also valued on face-to-face communication: "I'd rather prefer to talk personally to people, because I think talking to people you have an interaction that you cannot have if you see a screen." Others posited that videoconferencing would be "kind of mechanical; too impersonal." Participants felt that clinicians would be less rushed in person than over the phone or over videoconferencing. They did not think that doctors had enough time to conduct a visit over the phone, and expressed that sitting down face-to-face across from a clinician would ensure that the clinician would not rush them.

Clinic visits as relationship building. Interestingly, some participants expressed that doctor's appointments, rather than being an inconvenience, were a good excuse to get out of their house. Most participants had a system for finding transportation to and from medical visits, and seemed to view them as a social outlet. One participant explained, "I have time." 


\section{Positive Attitudes Towards Telemedicine}

Baseline familiarity with technology. Participants who expressed positive attitudes towards telemedicine were much more likely to be those who had some baseline level of comfort with technology, such as using email, Skype, YouTube, or online support groups. Some had prior positive experiences with telemedicine such as using a patient portal to view test results and contact their clinicians. Participants who already felt comfortable using the phone to consult with the doctor (for example, to obtain advice about whether to go to the emergency room) were most open to conducting a clinical visit over the phone.

Convenience of telemedicine. Those who were most strongly in favor of using telemedicine mentioned the benefits in terms of convenience and saving time. Participants appreciated that they would be able to avoid transportation hassles, and one stated that he only wanted to go into the doctor's office for in-person visits "if it's really necessary." Other participants were eager to use monitoring technology that automatically sends their physiologic parameters to the doctor's office so that they would not have to keep track of those measurements themselves. Some participants felt that telemedicine options would be particularly favorable during the wintertime, when traveling to clinic visits is especially burdensome.

Of note, some participants did mention that they would only be comfortable with telemedicine consults if they occurred in the context of a long-term relationship with a clinician.

\section{Discussion}

Telemedicine has shown remarkable promise in increasing access, improving outcomes, and reducing costs in the care of homebound patients. However, a large portion of homebound patients refuse to use telemedicine as part of their health care (Choi et al., 2014a). 
Our study employed qualitative interviews to investigate the underlying reasons behind homebound patients' hesitance in accepting telemedicine. The majority of participants were unenthusiastic about telemedicine approaches. This study is in keeping with other research that has described patients' largely negative attitudes towards telemedicine, but builds upon prior work by focusing on homebound patients, who stand to benefit the most from telemedicine interventions, and by describing in detail the barriers towards telemedicine adoption (Call et al., 2015; Eikelboom \& Atlas, 2005).

Prior studies have shown that once patients are exposed to telemedicine, their acceptance increases and they express interest in continuing in these programs (Choi et al., 2014c; Cranen, Veld, Ijzerman, \& Vollenbroek-Hutten, 2011; Finkelstein et al., 2004; Gellis et al., 2014; Mair \& Whitten, 2000). However, patients who have deeply held beliefs that using these types of technology is too troublesome may be reluctant to even try telemedicine. One solution may be to perform in-home or peer-to-peer demonstrations of simple videoconferencing, telemonitoring equipment, and other telemedicine interventions to show patients what is entailed before asking patients to adopt them. Harnessing a patient's pre-existing trust in a visiting nurse by training the nurse to teach the patient to use the new technology may also help encourage adoption. Studies have shown that patients are often surprised by the convenience, ease of use, and in-person-like qualities of interacting with a clinician through videoconferencing (Choi et al., 2014b).

Participants placed a very high value on in-person office visits. While other studies have reported patient preference for in-person clinical encounters, this has not been described before in the homebound population, and is especially compelling considering the substantial burden and effort it takes for them to arrange transportation and get out of the house (Bürmann Genannt Siggemann, Mensing, Classen, Hornberg, \& Terschuren, 2013; Call et al., 2015; Turner, 
Thomas, \& Reinsch, 2004). In order to address homebound patients' desire for continued inperson interaction with their clinicians, it may be beneficial if telemedicine approaches were incorporated into pre-existing relationships of the patient's care team. As trust and rapport have already been established during in-person visits, communicating over unfamiliar means may be more acceptable and possibly more effective. It may also be helpful to emphasize to patients that telemedicine can create more connections (with greater access to specialists and therapists and more frequent access to primary care providers and telehealth nurses), rather than erode existing ones.

We also found that participants who were already technologically savvy were those with the most positive attitudes towards telemedicine. While this is anticipated, it highlights the underlying technology gap that may be driving many of the reservations homebound patients have towards telemedicine. Addressing this fundamental digital divide, such as by offering computer classes or discounted tablet devices, may help not only increase acceptance of telehealth interventions, but also give homebound patients new skills and a means of connecting with the outside world. While home care agencies and clinicians may not be the ones to tackle the technology gap themselves, the health care community can raise awareness about how this type of disparity affects patients' health and support measures to reduce the divide as our patients' advocates.

These results must be interpreted in the context of the study design. Although the number of patients in this study is limited, prior work in qualitative analysis has found saturation of themes at 12 participants, and we feel confident that our interviews with 17 participants captured the breadth of patient attitudes towards telemedicine (Guest, Bunce, \& Johnson, 2006). Another limitation of our study is that the majority of our participants were referred by one of 
our partner home care agencies, which serves a mostly inner-city population in Boston. Thus, there was likely an overrepresentation of patients who are minorities and who are of low socioeconomic status. Many of our participants may be technologically disadvantaged at baseline, and populations with greater resources may have different opinions regarding telemedicine. Future studies in different patient populations may help elucidate an even broader range of perspectives on this topic.

There is great potential for telemedicine to positively impact homebound patients' lives, health, and finances. However, uptake of telemedicine programs by patients and home care agencies remains lower than it could be (Bashshur, Shannon, Krupinski, \& Grigsby, 2013). Through qualitative interviews, our study probed the attitudes of homebound patients towards technology and telemedicine, and found two main barriers - lack of familiarity with technology and desire for in-person clinic visits - to participants' acceptance of telemedicine. Addressing these concerns will be critical to pave the road for broad adoption of telemedicine as a routine part of the care of homebound patients.

\section{Acknowledgments}

We would like to thank Eileen Segale of Upham's Home Care for her invaluable assistance.

\section{Funding}

This project was financially supported by the Martin P. Solomon Scholars Fund. 


\section{References}

Bashshur, R.L., Shannon, G., Krupinski, E.A., \& Grigsby, J. (2013) Sustaining and realizing the promise of telemedicine. Telemed J E Health, 19, 339-345.

Bürmann Genannt Siggemann, C., Mensing, M., Classen, T., Hornberg, C., \& Terschuren, C. (2013) Specific health status has an impact on the willingness to use telemonitoring: Data from a 2009 health survey in North Rhine-Westphalia, Germany. Telemed JE Health, 19, $692-698$.

Call, V.R., Erickson, L.D., Dailey, N.K., Hicken, B.L., Rupper, R., Yorgason, J.B. and Bair, B. (2015) Attitudes toward telemedicine in urban, rural, and highly rural communities. Telemed J E Health, 21, 644-51.

Centers for Medicare \& Medicaid Services. (2012) Medicare and Medicaid statistical supplement, 2012. Table 7.2. Persons served, visits, total charges, visit charges, and program payments for Medicare home health agency services: Calendar year 2011. Washington, DC. Retrieved from http://cms.hhs.gov/Research-Statistics-Data-andSystems/Statistics-Trends-and-Reports/MedicareMedicaidStatSupp/2012.html.

Centers for Medicare \& Medicaid Services. (2013) Home health: Clarification to benefit policy manual language on "confined to the home" definition.

https://www.cms.gov/Regulations-and-

Guidance/Guidance/Transmittals/downloads/R172BP.pdf, accessed 9 August 2016.

Choi, N.G., Wilson, N.L., Sirrianni, L., Marinucci, M.L., \& Hegel, M.T. (2014a) Acceptance of home-based telehealth problem-solving therapy for depressed, low-income homebound older adults: qualitative interviews with the participants and aging-service case managers. Gerontologist, 54, 704-13. 
Choi, N.G., Marti, C.N., Bruce, M.L., Hegel, M.T., Wilson, N.L. \& Kunik, M.E. (2014b) Sixmonth postintervention depression and disability outcomes of in-home telehealth problem-solving therapy for depressed, low-income homebound older adults. Depress Anxiety, 31, 653-61.

Choi, N.G., Hegel, M.T., Marti, N., Marinucci, M.L., Sirrianni, L., \& Bruce, M.L. (2014c) Telehealth problem-solving therapy for depressed low-income homebound older adults. Am J Geriatr Psychiatry, 22, 263-71.

Crabtree, B.F., \& Miller, W.L. (1999) Doing Qualitative Research. Thousand Oaks, CA: Sage, $179-184$

Cranen, K., Veld, R.H., Ijzerman, M., \& Vollenbroek-Hutten, M. (2011) Change of patients' perceptions of telemedicine after brief use. Telemed JE Health, 17, 530-535.

Criss S, Woo Baidal JA, Goldman RE, Perkins M, Cunningham C, \& Taveras EM. (2015) The role of health information sources in decision-making among Hispanic mothers during their children's first 1000 days of life. Matern Child Health J, 19, 2536-43.

Crotty BH, Walker J, Dierks M, Lipsitz L, O'Brien J, Fischer S, Slack WV, \& Safran C. (2015) Information sharing preferences of older patients and their families. JAMA Intern Med, $175,1492-1497$.

Dallaghan GL, Hoffman E, Lyden E, \& Bevil C. (2016) Faculty attitudes about interprofessional education. Med Educ Online, 21, 32065. doi: 10.3402/meo.v21.32065.

Eikelboom, R.H., \& Atlas, M.D. (2005) Attitude to telemedicine, and willingness to use it, in audiology patients. J Telemed Telecare, 11, 22-25.

Finkelstein, S.M., Speedie, S.M., Demiris, G., Veen, M., Lundgren, J.M. \& Potthoff, S. (2004) Telehomecare: quality, perception, satisfaction. Telemed J E Health, 10, 122-8. 
Gellis, Z.D., Kenaley, B., McGinty, J., Bardelli, E., Davitt, J., \& Ten Have, T. (2012) Outcomes of a telehealth intervention for homebound older adults with heart or chronic respiratory failure: a randomized controlled trial. Gerontologist, 52, 541-52.

Gellis, Z.D., Kenaley, B.L., \& Ten Have T. (2014) Integrated telehealth care for chronic illness and depression in geriatric home care patients: the Integrated Telehealth Education and Activation of Mood (I-TEAM) study. J Am Geriatr Soc, 62, 889-95.

Guest, G., Bunce, A., \& Johnson, L. (2006) How many interviews are enough? Field Methods, $18,59-82$.

Mair, F., \& Whitten, P. (2000) Systematic review of studies of patient satisfaction with telemedicine. $B M J, 320,1517-1520$.

Matthias MS, Kukla M, McGuire AB, Damush TM, Gill N, \& Bair MJ. (2016) Facilitators and barriers to participation in a peer support intervention for veterans with chronic pain. Clin J Pain, 32, 534-40.

Mohamed NE, Herrera PC, Hudson S, Revenson TA, Lee CT, Quale DZ, Zarcadoolas C, Hall SJ, \& Diefenbach MA. (2014) Muscle invasive bladder cancer: Examining survivor burden and unmet needs. J Urology, 191, 48-53.

National Association for Home Care and Hospice. (2008). Philips National Study on the Future of Technology and Telehealth in Home Care. Andover, MA.

Ornstein, K.A., Leff, B., Covinsky, K.E., Ritchie, C.S., Federman, A.D., Roberts, L., Kelley, A.S., Siu, A.L., \& Szanton, S.L. (2015) Epidemiology of the homebound population in the United States. JAMA Intern Med, 175, 1180-1186.

Rees, R.S., \& Bashshur, N. (2007) The effects of TeleWound management on use of service and financial outcomes. Telemed J E Health, 13, 663-74. 
Sheeran, T., Rabinowitz, T., Lotterman, J., Reilly, C.F., Brown, S., Donehower, P., Ellsworth, E., Amour, J.L., Bruce, M.L. (2011) Feasibility and impact of telemonitor-based depression care management for geriatric homecare patients. Telemed $J$ E Health, 17, $620-6$.

Tomuro, K. Development of oral home telecare programme for the home-dwelling elderly: a pilot study. (2004) Gerodontology, 21, 177-80.

Turner, J.W., Thomas, R.J., \& Reinsch, N.L. (2004) Willingness to try a new communication technology: Perceptual factors and task situations in a health care context. J Bus Commun, 41, 5-26.

U.S. Department of Health and Human Services. (2012) 2000 National Home and Hospice Care Survey. Centers for Disease Control and Prevention, CD Rom Series 13, No. 31.

Hyattsville, MD: National Center for Health Statistics, 2012. 